\title{
The Use of Cosolvents in Heterogeneously and Homogeneously Catalyzed Methanolysis of Oil
}

\author{
Martin Hájek $^{1 *}$, Aleš Vávra ${ }^{1}$, Petr Mach $^{1}$, Anna Straková ${ }^{1}$ \\ ${ }^{1}$ Department of Physical Chemistry, Faculty of Chemical Technology, University of \\ Pardubice, Studentská 573, 53210 Pardubice, Czech Republic
}

*Correspondence author: Martin.Hajek2@upce.cz 


\section{ABSTRACT}

1 The paper describes transesterification of oil by methanol with use of cosolvents such as ethyl

2 acetate, tetrahydrofuran, hexane, acetone and diethyl ether at catalyst homogeneous (potassium 3 hydroxide) and heterogeneous (mixed oxides). The cosolvents dissolve oil and methanol to form

4 a single (homogeneous) phase, which increases the reaction rate. Therefore, the biodiesel 5 production will be environmentally friendly because less energy is consumed, which increases

6 sustainability. The whole binodal curve of ternary plots of oil, methanol and cosolvent was 7 determined to find the molar ratio, in which the reaction mixture forms a single phase. The ethyl acetate and tetrahydrofuran have relatively small heterogeneous region, because of the similarity

9 of their electric dipole moment with methanol. After transesterification, the detailed analysis of ester and also glycerol phase was carried out. For homogeneous catalyst, the highest esters

11 content in the ester phase was achieved with tetrahydrofuran. For heterogeneous catalyst, the 12 ester content was lower with cosolvent than without cosolvent, probably due to dilution of reaction components by cosolvent or bonding of cosolvent to the active sites of the catalyst.

\section{KEYWORDS}

15 methyl ester; transesterification; cosolvents; ternary plot; heterogeneous catalyst; 16 homogeneous catalyst

\section{NOMENCLATURE}

$18 \mathrm{AC}$

19 DEE

20 DG

21 ETAC

22 EP

23 FAME

$24 \mathrm{GC}$

25 GP
Acetone

Diethyl ether

Diacylglycerides

Ethyl acetate

Ester phase

Fatty acid methyl ester

Gas chromatography

Glycerol phase 


\begin{tabular}{|c|c|c|}
\hline 26 & HEX & Hexane \\
\hline 27 & MET & Methanol \\
\hline 28 & MG & Monoacylglycerides \\
\hline 29 & $\mathrm{O}$ & Oil \\
\hline 30 & TG & Triacylglycerides \\
\hline 31 & THF & Tetrahydrofuran \\
\hline 32 & & \\
\hline 33 & an & Acid number $\left(\mathrm{mg} \mathrm{g}^{-1}\right)$ \\
\hline 34 & $K$ & Concentration of potassium ions $\left(\mathrm{mg} \mathrm{kg}^{-1}\right)$ \\
\hline 35 & $w_{\text {water }}^{E P}$ & Content of water in the EP (ppm) \\
\hline 36 & $w_{\text {water }}^{G P}$ & Content of water in GP (wt $\%)$ \\
\hline 37 & $w_{\text {ester }}$ & Ester content in the $\mathrm{EP}(\mathrm{wt} \%)$ \\
\hline 38 & $w_{M G}$ & Content of MG (wt\%) \\
\hline 39 & $w_{D G}$ & Content of DG (wt\%) \\
\hline 40 & $w_{T G}$ & Content of TG (wt\%) \\
\hline 41 & $w_{\text {ester }}^{G P}$ & Ester content in the GP (wt $\%)$ \\
\hline 42 & $w_{\text {glycerol }}$ & Content of glycerol in the GP (wt\%) \\
\hline 43 & $w_{K_{2}} \mathrm{CO}_{3}$ & Content of potassium carbonate in the GP (wt \%) \\
\hline 44 & $w_{\mathrm{KHCO}_{3}}$ & Content of potassium bicarbonate in the GP (wt $\%)$ \\
\hline 45 & $w_{K_{2} \mathrm{HPO}_{4}}$ & Content of dipotassium phosphate in the GP (wt\%) \\
\hline 46 & $w_{S}$ & Content of soap in the GP (wt\%) \\
\hline 47 & $v$ & Viscosity of EP $\left(\mathrm{mm}^{2} \mathrm{~s}^{-1}\right)$ \\
\hline 48 & $\rho$ & Density of EP $\left(\mathrm{g} \mathrm{cm}^{-3}\right)$ \\
\hline
\end{tabular}

$49 \quad 1$ Introduction

50 Biodiesel - the mixture of methyl esters of higher fatty acids is an alternative fuel for

51 combustion engines. It belongs to the renewable resources of energy and can be used in

52 current diesel engines without any modification. The carbon balance of biodiesel is zero, 53 because carbon dioxide formed by combustion is removed by photosynthesis of plants and 54 converted back into oil. Therefore it is sustainable source of energy. Moreover, biodiesel is 
nontoxic ecological fuel, which does not contain sulphur or aromatic hydrocarbons and it is also biodegradable (Yildiz et al., 2019).

It is usually synthesized by transesterification of triacylglycerides (TG) with low molecular alcohols (most often methanol - MET), which is mostly catalyzed by homogeneous (Gardy et al., 2019). The use of heterogeneous catalysts such as mixed metal oxide (Banerjee et al., 2019) is also possible. The sources of TG are vegetable oils, animal fats or waste cooking oils (Cordero-Ravelo and Schallenberg-Rodriguez, 2018). The use oils from algae was published (Passell et al., 2013). The TG and methanol are immiscible liquids, i.e. heterogeneous mixture is formed and the reaction proceeds on the interface. To increase the reaction rate (i.e. to shorten the reaction time): (i) the reaction mixture has to be intensively stirred or (ii) a cosolvent can be added. The cosolvents are inactive to reaction components and solve both raw materials to single phase, i.e. homogeneous mixture is formed. The use of cosolvents decreases the production costs by decreasing of (i) reaction time or (ii) reaction temperature. Total production process will consume less energy and so be more sustainable.

The most commonly used cosolvents are organic solvents with relatively similar boiling point to methanol. The use of several cosolvents, mostly for homogeneously catalysed transesterification, could be found in the literature, such as acetone (AC), ethyl acetate (ETAC), tert-butyl methyl ether dimethyl ether, di-isopropyl ether, tetrahydrofutran (THF) (Ataya et al., 2006). Todorovic et al. published use of THF (from 0\% to 50\% based on the oil mass) as a cosolvents for transesterification of sunflower oil catalysed by potassium hydroxide $(\mathrm{KOH})$ at $10{ }^{\circ} \mathrm{C}$. They found that maximum yield of fatty acid methyl ester (FAME) was $90 \mathrm{wt} \%$ for optimum $50 \mathrm{wt} \%$ of THF to make the reactants completely miscible at the reaction temperature of $20^{\circ} \mathrm{C}$ (Todorovic et al., 2013). Alhassan et al. tested three types of cosolvents (DEE, dichlorbenzene and AC) in transesterification of cotton oil with methanol and $\mathrm{KOH}$ as the catalyst. The optimal volume of cosolvents added to methanol was found 
10 vol\% for dichlorbenzene and AC and about 30 vol\% for DEE. The authors also found that the addition of cosolvents does not affect the properties of the fuel (Alhassan et al., 2014). Another author, also used AC as the cosolvent for homogeneous transesterification of canola oil with methanol catalysed by $\mathrm{KOH}$ and found that optimal reaction conditions were $25 \mathrm{wt} \%$ of AC, $1 \mathrm{wt} \%$ of $\mathrm{KOH}$ and a molar ratio of methanol to oil of 4.5:1 (Thanh et al., 2013). Guan et al. carried out transesterification of sunflower oil with methanol (the molar ratio methanol to oil 6:1) by using $\mathrm{KOH}$ as the catalyst in the presence of various cosolvents (dimethyl ether, tert-butyl methyl ether, DEE and THF) at $25^{\circ} \mathrm{C}$. They determined minimum molar ratio of cosolvent and methanol for each cosolvent necessary for total dissolution of methanol and sunflower oil. The oil was completely converted into biodiesel after 20 minutes in comparison with $78 \%$ without cosolvents. Moreover, they found, that the addition of excess cosolvents decreased the reaction rate due to high dilution of the reaction mixture (Guan et al., 2009).

For heterogeneous catalyst, the cosolvent is also applicable. The calcium dioxide was used as heterogeneous catalyst of sunflower oil by methanol, where the crude biodiesel was used as cosolvent (Todorovic et al., 2019).

The aim is to describe and compare the influence of cosolvents on the course of transesterification and properties of both phases. The novelty especially consists in (i) the measurement of ternary plots including binodal curve for all molar ratios of oil, methanol and cosolvent such as tetrahydrofuran (THF), acetone (AC), ethyl acetate (ETAC), diethyl ether (DEE), hexane (HEX) and (ii) the detailed analysis of formed ester and glycerol phase including the ester loses (for homogeneous catalyst) after transesterification. The measurement of ternary plots and properties of both phases, which are very often omitted, are different from other papers. The importance lays in potential decreasing of transesterification time and temperature, which can improve economic and environmental impact of biodiesel production. 


\section{Materials and methods}

\subsection{Ternary plot}

107 The points of binodal curve at ternary plots were determined by spectrophotometric method

108 by measuring of the transmittance at constant wavelength $567 \mathrm{~nm}$ at laboratory temperature

$109\left(25^{\circ} \mathrm{C}\right)$, for $100 \%$ of transmittance, pure oil was used. The mixture of oil and methanol (in

110 certain molar ratio) was added into cuvette and stirred at $25^{\circ} \mathrm{C}$. The formed heterogeneous

111 mixture had low transmittance. The inert cosolvent, which is miscible with both liquids, was

112 consecutively added (the amount added was $100 \mu \mathrm{l}$ ) until the transmittance sharply increased

113 (almost at $100 \%$ ), as shown at Fig. 1.

114 Thus, one point of the binodal curve of the ternary plot was obtained. All binodal points for

115 all cosolvents, i.e. ethyl acetate, THF, hexane, acetone and diethyl ether (all p.a., Penta, Czech

116 Republic) at different molar ratios of oil and methanol were determined by this method. The

117 chosen properties of cosolvents are stated in Table 1. The final plots were created in program

118 Origin 9.1. Note that the oil is composed of many types of triacylglycerides with very similar 119 properties, which are not possible to separate. Hence oil was considered as chemical 120 individuum with molar mass of $879.1 \mathrm{~g} \mathrm{~mol}^{-1}$ (Komers et al., 2001).

\subsection{Transesterification of oil}

122 For homogeneous catalyst, $400 \mathrm{~g}$ of rapeseed oil (acid number $0.23 \mathrm{mg} \mathrm{KOH} \mathrm{g}^{-1}$, water 123 content $338 \mathrm{mg} \mathrm{kg}^{-1}$ produced by Ceresol, Czech Republic) was put into the reaction vessel. 124 The amount of $0.8 \mathrm{wt} \%$ of catalyst $\mathrm{KOH}$ (purity $85 \mathrm{wt} \%$, Lach-Ner, Neratovice, Czech 125 Republic) to oil was dissolved in the mixture of methanol (p.a., Penta, Czech Republic) and 126 cosolvents (one of the ETAC, THF, HEX, AC and DEE). The exact cosolvent amount was

127 added so that the reaction mixture was in single phase. The mixture was thermostated to $25^{\circ} \mathrm{C}$ 128 (at atmospheric pressure) and then poured into the reaction vessel and stirred at $200 \mathrm{rpm}$; this 
point was considered as the start of transesterification. The reaction mixture was sampled at

130 time intervals $(10,20,30,50$ and $90 \mathrm{~min})$ and analysed with a respect to reaction

131 intermediates (mono-, di-, and triglycerides) and the main reaction product (esters). The

132 reaction was stopped by immediate neutralization of the catalyst by addition of $5 \mathrm{ml}$ of

$1330.2 \mathrm{~mol} \mathrm{dm}{ }^{-3}$ hydrochloric acid $(\mathrm{HCl})$.

134 After reaction time (90 $\mathrm{min})$, the reaction was stopped by neutralization of the catalyst by

135 gaseous carbon dioxide (weak acid) (Hajek et al., 2012) or phosphoric acid (relatively strong

136 acid). For neutralization by $\mathrm{CO}_{2}, \mathrm{pH}$ was monitored and when decreased to constant value

137 (approximately 9), the catalyst was neutralized. For neutralization by $\mathrm{H}_{3} \mathrm{PO}_{4}$, the amount of

138 catalyst remaining after reaction was necessary to determine by potentiometric titration and an

139 equivalent amount of acid was added (Vavra et al., 2018). The excess of alcohol and

140 cosolvents was removed by distillation under reduced pressure (approximately $3 \mathrm{kPa}$ ) and

141 higher temperature $\left(70{ }^{\circ} \mathrm{C}\right)$. Then, the mixture was separated by gravity for $24 \mathrm{~h}$ in the

142 separatory funnel. After separation, both formed phases (the ester and glycerol phases) were

143 analysed.

144 For heterogeneous catalyst $-\mathrm{Mg}$ - $\mathrm{Al}$ mixed oxides were synthesized from hydrotalcites by

145 heating (calcination) to $450{ }^{\circ} \mathrm{C}$ for $3 \mathrm{~h}$, the detailed synthesis process was described (Hajek et

146 al., 2015). The real molar ratio $\mathrm{Mg}$ :Al was 4.5:1. The reaction was carried out in stainless

147 steel batch autoclave (300 ml, Parr company, USA) equipped with shaft stirrer. The amount

148 of $30 \mathrm{~g}$ of rape seed oil, $32 \mathrm{ml}$ of methanol (PENTA s.r.o., p.a.), $12 \mathrm{ml}$ of cosolvent and $1 \mathrm{~g}$ of

149 catalyst were placed to the reactor. After heating to the reaction temperature $\left(120^{\circ} \mathrm{C}\right)$, the

150 stirring was switched on $(300 \mathrm{rpm})$ and the reaction, which takes 6 hours, was initiated. After

151 reaction time, the catalyst was removed by filtration and methanol by distillation from the

152 mixture $\left(70{ }^{\circ} \mathrm{C}, 3 \mathrm{kPa}\right)$. The mixture was analysed. 


\subsection{Analytical method}

154 The contents of glycerides were determined by gas chromatography with flame ionization detector (GC-2010, Shimadzu, Japan) according to EN 14105 with the help of linear calibration curves (monoolein, diolein and triolein were used as standards). The content of

157 esters in the EP ( $w_{\text {ester }}$ in wt $\%$ ) was calculated as the difference of $100 \%$ minus the sum of 158 concentrations of all glycerides in the EP (providing that the concentrations of other 159 substances in the EP are insignificant).

160 For homogeneous catalyst, the content $(\mathrm{mg} / \mathrm{kg})$ of potassium ions in the EP was 161 determined by flame photometry (Flame photometer 410, Sherwood Scientific Ltd, United 162 Kingdom). The flash point of the EP was measured by the Pensky-Martens closed-cup method (EN ISO 2719) with the instrument OB-305 (MIM Fabri, Hungary). The water content in both

164 phases was determined according to EN ISO 12937 (TitroLine $® 7750$ ). In the GP, the 165 contents of basic matter (potassium hydrogen carbonate, potassium carbonate, $\mathrm{K}_{2} \mathrm{HPO}_{4}$ and 166 soaps) were determined by acidimetric titration by $\mathrm{HCl}\left(0.1 \mathrm{~mol} \mathrm{dm}^{-3}\right)$ with potentiometric identification (Kwiecien et al., 2009). The content of glycerol and esters (i.e. esters loss) in the GP was determined by HPLC (Hajek et al., 2010).

169 The heterogeneous catalyst was characterised by XRD and TGA to confirm the successful 170 synthesis (Hajek et al., 2015).

\section{$171 \quad 3 \quad$ Results and discussion}

\subsection{Ternary plots}

173 The main reaction components methanol and oil are immiscible liquids (i.e. heterogeneous

174 system is formed), so the transesterification proceeds on the interphase. The addition of 175 cosolvent, which is miscible with oil and also with methanol, forms the homogeneous mixture 176 (single phase). 
Firstly, the ternary plots for methanol, rapeseed oil (Oil) and all cosolvents (ETAC, THF,

178 HEX, AC and DEE) were determined at constant temperature $25{ }^{\circ} \mathrm{C}$ (Fig 2). Moreover, the molar ratio of oil to methanol 1:6, which is the most often used, was also marked in the plots (red line). The chosen properties of cosolvents (Rumble, 2019) including the minimum molar ratio of components for the mixture in the single phase are stated in Table 1.

The aim was to find the molar ratio between methanol, oil and cosolvent, so that the reaction mixture was in single phase (homogeneous). The binodal curve of ternary plots was completely determined, which enabled to find homogeneous region for any molar ratio of methanol to oil. This is the difference from paper published by Todorovic et al., where authors used sunflower oil and determined single "region" only for one molar ratio of methanol to oil at $60{ }^{\circ} \mathrm{C}$ (Todorovic et al., 2013). Authors Khang et al. determined the ternary plot for methanol, oil and THF (in volume percent), but only for quite narrow part of binodal curve: from 0.1 to 0.25 vol\% of coconut oil in mixture (Khang et al., 2014). The ternary plots especially for THF as cosolvent with different types of oil such as canola, soybean and palm were determined (in volume percent) at $23{ }^{\circ} \mathrm{C}$. Another authors used visual indication of cloud point, which is less precisely than indication by transmittance. Moreover, they used volume ratio methanol/oil from 0.1 to 0.9 , so without determination of the lowest ratios. The superimposition of ternary diagrams revealed that for some oils were virtually identical. Authors carried out on transesterification of soybean oil, but without any analysing of product in detail (Boocock et al., 1996).

The heterogeneous region was smaller for ETAC, THF and DEE in comparison with HEX and $\mathrm{AC}$ (Fig 2). The reason is the electric dipole moment, which corresponds to the polarity of chemical substances (Table 1). The dipole moments for ETAC $(1.78 \mathrm{C} \mathrm{m})$, THF $(1.63 \mathrm{C} \mathrm{m})$ and DEE $(1.15 \mathrm{C} \mathrm{m})$ have similar value as the methanol itself $(1.69 \mathrm{C} \mathrm{m})$, so these solvents are relatively miscible, i.e. small amount of cosolvent has to be added to reaction mixture to form 
single phase. The dipole moments of cosolvents $\operatorname{HEX}(0.08 \mathrm{C} \mathrm{m})$ and $\mathrm{AC}(2.91 \mathrm{C} \mathrm{m})$ are

203 significantly different from dipole moment of methanol $(1.69 \mathrm{C} \mathrm{m})$, which has smaller single region, i.e. large amount of cosolvent has to be added to reaction mixture so it was homogeneous. Todorovic at al. published lower molar ratio so that the mixture was homogeneous, but at higher temperature $\left(60^{\circ} \mathrm{C}\right)$ and standard pressure. This finding corresponds with the fact that solubility usually increases with increasing temperature, i.e. heterogeneous region is smaller. However, there is not described in detail how the molar ratio was found out, especially for DEE which has boiling point at $34.5^{\circ} \mathrm{C}$ (at standard pressure), i.e. at $60{ }^{\circ} \mathrm{C}$ has to be huge amount of this matter in gas phase (Todorovic et al., 2013).

\subsection{Transesterification - homogeneous catalyst}

The transesterification with addition of cosolvent was tested at homogeneous catalyst $(\mathrm{KOH})$. The course of transesterification, i.e. the dependency of the content of formed ester $\left(w_{\text {ester }}\right)$ on time was determined for cosolvents and compared with the course without cosolvents under the same reaction conditions (Fig. 3). The relatively low temperature $\left(25^{\circ} \mathrm{C}\right)$ was chosen because (i) the reaction mixture is not possible to heat more than the boiling point of less volatile component, e.g. boiling point of DEE is $34.5^{\circ} \mathrm{C}$ (at standard pressure) (ii) the reaction rate decreases with decreasing temperature so at lower temperature the courses are better comparable (reaction is relatively slow).

In addition, the transesterification was stopped by neutralisation of remained catalyst by two types of acids: gas $\mathrm{CO}_{2}$ as weak acid (Hajek et al., 2012) and by concentrated $\mathrm{H}_{3} \mathrm{PO}_{4}$ as a relatively strong acid (Vavra et al., 2018). After separation, the properties of the ester phase and glycerol phase were determined including ester losses in the GP.

The highest content of ester in the EP $\left(w_{\text {ester }}\right)$ for all reaction times was achieved with THF (more than $90 \mathrm{wt} \%$ after $90 \mathrm{~min}$ of reaction). The complete transformation of oil to ester was 
not achieved because low temperature $\left(25^{\circ} \mathrm{C}\right)$ was chosen. The EP, formed by

227 transesterification with cosolvents ETAC and DEE, has slightly less ester content than the EP 228 formed without cosolvents (approximately $85 \mathrm{wt} \%$ ). The lowest ester content was achieved

229 with acetone and hexane, because huge amount of these cosolvents had to be added so that the 230 mixture was in the single phase (table 1). This caused decreasing of concentration of oil and 231 methanol decrease and thereby decreased of reaction rate. However, Alhassan et al. carried out 232 the transesterification with diethyl ether and acetone as cosolvents at $60{ }^{\circ} \mathrm{C}$ (at standard 233 pressure) with bath reactor equipment by condenser unit. They achieved high yield of esters 90-100 wt\%, which depended on concrete reaction conditions (Alhassan et al., 2014). Higher content of ester was caused by higher temperature. Although authors used condenser unit, the boiling point of reaction mixture had to be similar as boiling point of the least volatile component i.e. diethyl ether (boiling point $34.5^{\circ} \mathrm{C}$ at standard pressure). Therefore, the reaction mixture cannot be heated to $60^{\circ} \mathrm{C}$ with diethyl ether (real temperature has to be much lower), or diethyl ether has to be present in vapour and not in liquid phase (it is not specified how much 240 the reactor was filled with liquid phase and how much "empty" space remained for gas phase). 241 Similarly for acetone (boiling point at $56.5^{\circ} \mathrm{C}$ ).

242 The properties of the EP are stated in Table 2. The content of mono-, di- and triglycerides is 243 relatively high, which is consistent with the ester content; higher content of glycerides means 244 lower content of esters. The density $(\rho)$ of EP was in the range $0.82-0.89 \mathrm{~g} \mathrm{~cm}^{-3}$ for all types of 245 cosolvents and ways of stopping. The viscosity $(v)$ was determined $5.1-5.5 \mathrm{~mm}^{2} \mathrm{~s}^{-1}$, which 246 was slightly higher than for methyl esters prepared without cosolvents $\left(4.9 \mathrm{~mm}^{2} \mathrm{~s}^{-1}\right)$, because 247 the EP contains glycerides, which increase the viscosity. Moreover, viscosity is slightly lower 248 for stopping by phosphoric acid than by gas carbon dioxide. The acid number (an) is less than $2490.4 \mathrm{mg} \mathrm{KOH} \mathrm{g}^{-1}$, because both ways of catalyst neutralisation ensure low acid number, i.e. the 250 transformation of soap (formed by side reaction) to higher fatty acid does not proceed (Vavra et 
al., 2018). The flash point of the EP was more than $120^{\circ} \mathrm{C}$ for all cosolvents, which means

252 almost no methanol or cosolvent were presented. The content of water in the EP $\left(w_{\text {water }}^{E P}\right)$ was 253 higher than for transesterification without the cosolvent $(650 \mathrm{ppm})$, because the cosolvents 254 contain small amount of water, which was presented in reaction mixture and remained after 255 methanol removal by distillation. The highest water in the EP was for AC because (i) AC 256 contains the highest water content and (ii) there was added the most amount from all cosolvents. 257 The content of potassium ions $(K)$ was also quite high. Note: The content of $w_{w a t e r}^{E P}$ and $K$ were 258 determined directly in EP after separation without any purification steps. Their content strongly 259 depends on the purification process and are not usually determined (Alhassan et al., 2014).

260 Moreover, the distribution of methyl esters according to higher fatty acid in the EP for 261 cosolvents was determined (Table 3). The content of methyl esters of linolenic acid is 262 approximately the same for THF and DEE and slightly higher for AC and ETAC than without 263 cosolvent. On the other hand, the content of methyl esters of linoleic acid was almost the 264 same for all cosolvents and also without cosolvent (ca $21 \%$ ). The content of the methyl esters 265 of oleic acid was the highest, which corresponds with the fatty acid profile of rapeseed oil. 266 The highest differences were for methyl esters of palmitic acid, where without cosolvent it 267 was $5.2 \%$, but for DEE the content was almost double (10.4\%). The differences in 268 distributions of methylesters are probably caused by the different polarity of cosolvents and 269 esters. The composition of the GP as a side product was also determined (Table 4).

270 The GP contains, besides glycerol $\left(w_{\text {glycerol }}\right)$, the formed soaps $\left(w_{\mathrm{s}}\right)$, the products of catalyst 271 neutralisation, water $\left(w_{\text {water }}^{G P}\right)$ and esters $\left(w_{\text {ester }}^{G P}\right)$. The product of catalyst neutralisation 272 depends on the type of neutralisation: carbonates $\left(w_{\mathrm{K}_{2} \mathrm{CO}_{3}}\right.$ and $\left.w_{\mathrm{KHCO}_{3}}\right)$ were formed by 273 neutralisation of $\mathrm{CO}_{2}$ and phosphates $\left(w_{K_{2} \mathrm{HPO}_{4}}\right)$ by $\mathrm{H}_{3} \mathrm{PO}_{4}$. The ester loss (determined as 274 content of ester in the GP) was higher for transesterification stopped by $\mathrm{H}_{3} \mathrm{PO}_{4}$ for all 275 cosolvents except ETAC. This is different from our previous finding regarding 
transesterification without cosolvent, where the ester content in the GP was higher just for

277 transesterification stopped by $\mathrm{CO}_{2}$ (Vavra et al., 2018). Therefore, the presence of cosolvents

278 in reaction mixture changes the amount of losses according to the way of transesterification

279 stop. The content of soaps was higher than without cosolvent (approximately $15 \mathrm{wt} \%$ ), which

280 indicates a side reaction process. The reason is probably that the reaction proceeds in a single

281 phase. Note: the total summa of weight percent is not exactly $100 \%$, because (i) the GP

282 contains small amount of other substances, such as methanol and vegetable dyes, which were

283 not determined and (ii) every analysis has some error (the highest error has glycerol

284 determination, because its concentration is high). However, the composition is not possible to

285 compare with other studies, because the GP is usually omitted.

\subsection{Transesterification - heterogeneous catalyst}

The Mg-Al mixed oxides with molar ratio $\mathrm{Mg} / \mathrm{Al} 4.5$ were used as heterogeneous catalyst.

288 This molar ratio was chosen because the activity of transesterification was quite high and not significantly changed by molar ratio increasing. The structures of Mg-Al hydrotalcite (as precursor) and also mixed oxides were confirmed by XRD analysis, where the characteristic diffraction lines were found (Fig. 4). The temperature stability of hydrotalcite was described by thermogravimetric analysis with mass detection (Fig. 5). Hydrotalcite are usually

293 decomposed in two or three consecutive steps (Yang et al., 2002). Our catalyst was 294 decomposed in two steps. In the first step $\left(100-250^{\circ} \mathrm{C}\right)$, only mass signal of water was found and therefore the surface water was desorbed. During the second step $\left(250-500{ }^{\circ} \mathrm{C}\right)$ carbonates from anion layer and another water were desorbed, for this reason mass signal of carbone dioxide and water were determined. The third did not occur. The total loss of mass 298 during the TGA analysis was approximately $46 \%$.

299 The content of ester in the ester phase was $42 \mathrm{wt} . \%$ for tetrahydrofuran, $39.5 \mathrm{wt} \%$ for ethyl acetate and diethyl ether and $29.6 \mathrm{wt} \%$ for hexane and acetone, which is lower than without 
cosolvent (72 wt \%). The decreasing is much lower than for homogeneous catalyst (section 3.2). The probable reason for so low ester content is (i) bonding of cosolvent to the active sites of catalyst, which are not available for transesterification or (ii) dilution of reaction components (methanol and oil) by cosolvent, which corresponds with the fact that hexane and acetone had to be added in higher amount than acetate and diethyl ether.

\section{Conclusions}

307 The work described the use of various cosolvents (form single phase) for transesterification of 308 oil by methanol. At first, the ternary plots including binodal curve for all molar ratios of oil to 309 methanol were determined. The lower molar ratios (mixture was in single phase) were 310 determined for ethyl acetate, tetrahydrofuran and diethyl ether, because their dipole moments 311 are relatively similar to dipole moment of methanol. The formation of esters and also final 312 content of ester in the ester phase was similar for all cosolvents except ethyl acetate. 313 However, the highest ester content was achieved for tetrahydrofuran (93.2 wt $\%)$. The use of

314 cosolvents does not significantly change the distribution of methyl esters according to higher 315 fatty acid (except methyl esters of palmitic acid). It was also found, that the cosolvents change 316 the amount of ester losses, which depends on the way of transesterification stop. The use of 317 cosolvent can decrease the production cost and improves the total energy balance of biodiesel 318 production, because it proceeds at lower temperature and shorter time. On the other hand, the 319 ester yield is slightly lower, because saponification is more intensive.

320 For heterogeneous catalyst, the ester content was lower with cosolvent than without 321 cosolvents, probably due to dilution of reaction components.

\section{Acknowledgements}

324 This work was supported by the Czech Science Foundation, Project No. 19-00669S. 
Alhassan, Y., Kumar, N., Bugaje, I.M., Pali, H.S., Kathkar, P., 2014. Co-solvents transesterification of cotton seed oil into biodiesel: Effects of reaction conditions on quality of fatty acids methyl esters. Energy Convers. Manage. 84, 640-648. https://doi.org/10.1016/j.enconman.2014.04.080

Ataya, F., Dube, M.A., Ternan, M., 2006. Single-phase and two-phase base-catalyzed transesterification of canola oil to fatty acid methyl esters at ambient conditions. Ind. Eng. Chem. Res. 45, 5411-5417. https://doi.org/10.1021/ie060152o

Banerjee, S., Sahani, S., Sharma, Y.C., 2019. Process dynamic investigations and emission analyses of biodiesel produced using Sr-Ce mixed metal oxide heterogeneous catalyst. J. Environ. Manage. 248. https://doi.org/10.1016/j.jenvman.2019.06.119

Boocock, D.G.B., Konar, S.K., Sidi, H., 1996. Phase diagrams for oil/methanol/ether mixtures. J. Am. Oil Chem. Soc. 73, 1247-1251. https://doi.org/doi 10.1007/Bf02525453

Cordero-Ravelo, V., Schallenberg-Rodriguez, J., 2018. Biodiesel production as a solution to waste cooking oil (WCO) disposal. Will any type of WCO do for a transesterification process? A quality assessment. J. Environ. Manage. 228, 117-129. https://doi.org/10.1016/j.jenvman.2018.08.106

Gardy, J., Rehan, M., Hassanpour, A., Lai, X.J., Nizami, A.S., 2019. Advances in nanocatalysts based biodiesel production from non-food feedstocks. J. Environ. Manage. 249. https://doi.org/10.1016/j.jenvman.2019.109316

Guan, G.Q., Sakurai, N., Kusakabe, K., 2009. Synthesis of biodiesel from sunflower oil at room temperature in the presence of various cosolvents. Chem. Eng. J. 146, 302-306. https://doi.org/10.1016/j.cej.2008.10.009

Hajek, M., Kutalek, P., Smolakova, L., Troppova, I., Capek, L., Kubicka, D., Kocik, J., Thanh, D.N., 2015. Transesterification of rapeseed oil by $\mathrm{Mg}$-Al mixed oxides with various Mg/Al molar ratio. Chem. Eng. J. 263, 160-167. https://doi.org/10.1016/j.cej.2014.11.006

Hajek, M., Kwiecien, J., Skopal, F., 2012. Biodiesel: The influence of dealcoholization on reaction mixture composition after neutralization of catalyst by carbon dioxide. Fuel 96, 8589. https://doi.org/10.1016/j.fuel.2012.01.037

Hajek, M., Skopal, F., Kwiecien, J., Cernoch, M., 2010. Determination of esters in glycerol phase after transesterification of vegetable oil. Talanta 82, 283-285. https://doi.org/10.1016/j.talanta.2010.04.035

Khang, D.S., Razon, L.F., Madrazo, C.F., Tan, R.R., 2014. In situ transesterification of coconut oil using mixtures of methanol and tetrahydrofuran. Chem. Eng. Res. Des. 92, 1512-1518. https://doi.org/10.1016/j.cherd.2014.01.002

Komers, K., Stloukal, R., Machek, J., Skopal, F., 2001. Biodiesel from rapeseed oil, methanol and $\mathrm{KOH} 3$. Analysis of composition of actual reaction mixture. Eur. J. Lipid Sci. Technol. 103, 363-371. https://doi.org/10.1002/1438-9312(200106)103:6<363::AidEjlt363>3.0.Co;2-3

Kwiecien, J., Hajek, M., Skopal, F., 2009. The effect of the acidity of rapeseed oil on its $\begin{array}{llll}\text { transesterification. } & \text { Bioresour. } & \text { Technol. } & \text { 5555-5559. }\end{array}$ https://doi.org/10.1016/j.biortech.2009.06.002

Passell, H., Dhaliwal, H., Reno, M., Wu, B., Ben Amotz, A., Ivry, E., Gay, M., Czartoski, T., Laurin, L., Ayer, N., 2013. Algae biodiesel life cycle assessment using current commercial data. J. Environ. Manage. 129, 103-111. https://doi.org/10.1016/j.jenvman.2013.06.055

Rumble, J., 2019. Handbook of Chemistry and Physics, 100 ed.

Thanh, L.T., Okitsu, K., Sadanaga, Y., Takenaka, N., Maeda, Y., Bandow, H., 2013. A new co-solvent method for the green production of biodiesel fuel - Optimization and practical application. Fuel 103, 742-748. https://doi.org/10.1016/j.fuel.2012.09.029 
Todorovic, Z.B., Stamenkovic, O.S., Stamenkovic, I.S., Avramovic, J.M., Velickovic, A.V., Bankovic-Ilic, I.B., Veljkovic, V.B., 2013. The effects of cosolvents on homogeneously and heterogeneously base-catalyzed methanolysis of sunflower oil. Fuel 107, 493-502. https://doi.org/10.1016/j.fuel.2012.11.049

Todorovic, Z.B., Troter, D.Z., Dokic-Stojanovic, D.R., Velickovic, A.V., Avramovic, J.M., Stamenkovic, O.S., Veselinovic, L.M., Veljkovic, V.B., 2019. Optimization of CaOcatalyzed sunflower oil methanolysis with crude biodiesel as a cosolvent. Fuel 237, 903-910. https://doi.org/10.1016/j.fuel.2018.10.056 addition of inorganic acid in biodiesel production. J. Clean. Prod. 192, 390-395. https://doi.org/10.1016/j.jclepro.2018.04.242

Yang, W.S., Kim, Y., Liu, P.K.T., Sahimi, M., Tsotsis, T.T., 2002. A study by in situ techniques of the thermal evolution of the structure of a Mg-Al-CO3 layered double hydroxide. Chem. Eng. Sci. 57, 2945-2953. https://doi.org/10.1016/S0009-2509(02)00185-9 of biodiesel and diesel fuels for a diesel engine. J. Environ. Manage. 243, 218-226. 


\section{$394 \quad$ Figure caption}

395 Fig. 1: The dependency of transmittance on time for determination of points of binodal curve

396 Fig. 2: The ternary plots of methanol, oil with various cosolvents: ETAC (A), THF (B), HEX (C), AC (D), DEE (E) at $25^{\circ} \mathrm{C}$ and atmospheric pressure; the molar ratio of oil to methanol 1:6 is marked by red line

399 Fig. 3: The dependency of content of ester in the EP $\left(w_{\text {ester }}\right)$ on the reaction time for various cosolvents at $25^{\circ} \mathrm{C}$ and $0.8 \mathrm{wt} \%$ of catalyst to oil

401 Fig. 4: The diffractogram of Mg-Al hydrotalcites (HT) and mixed oxides (HTc)

402 Fig. 5: TGA of Mg-Al hydrotalcites 


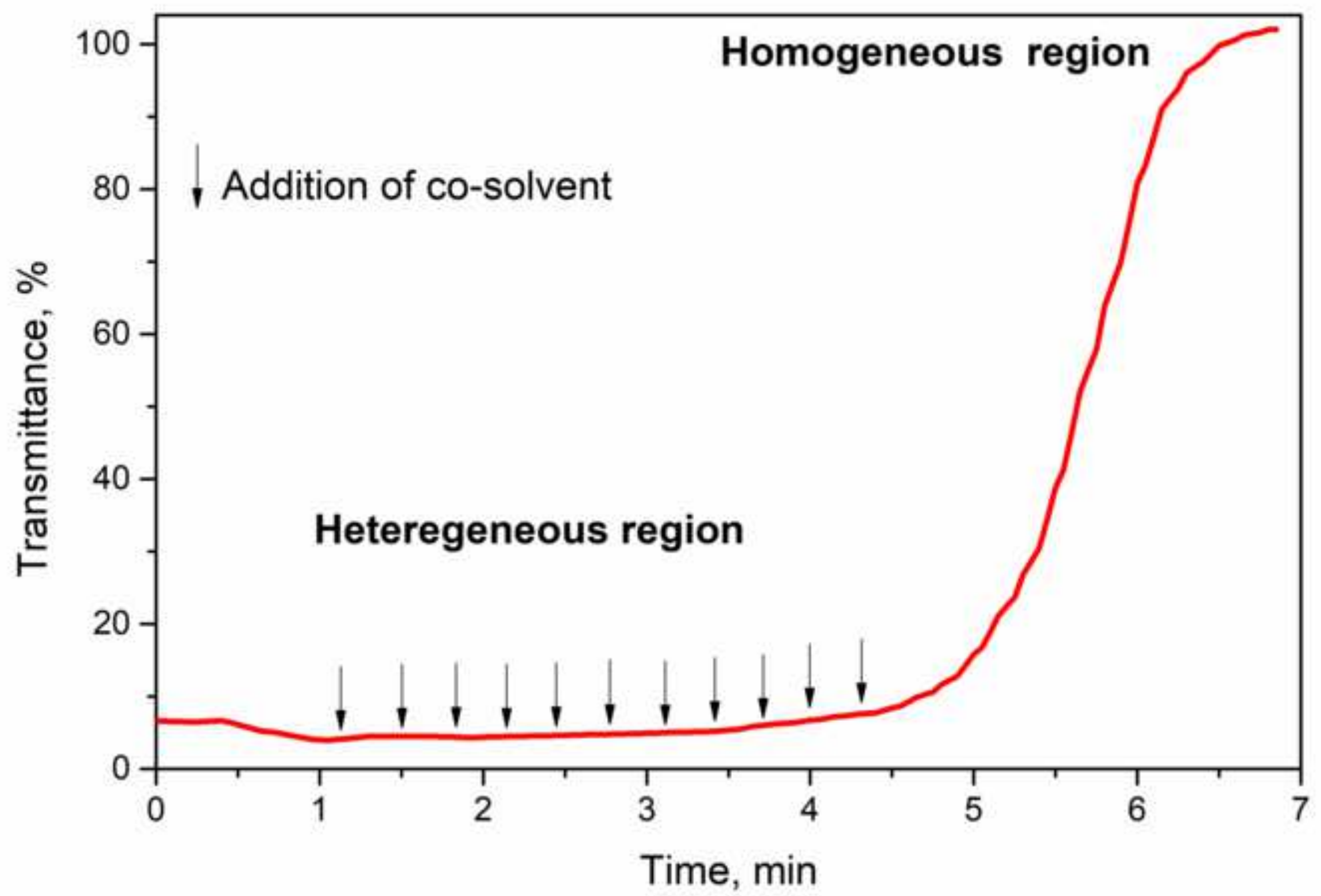



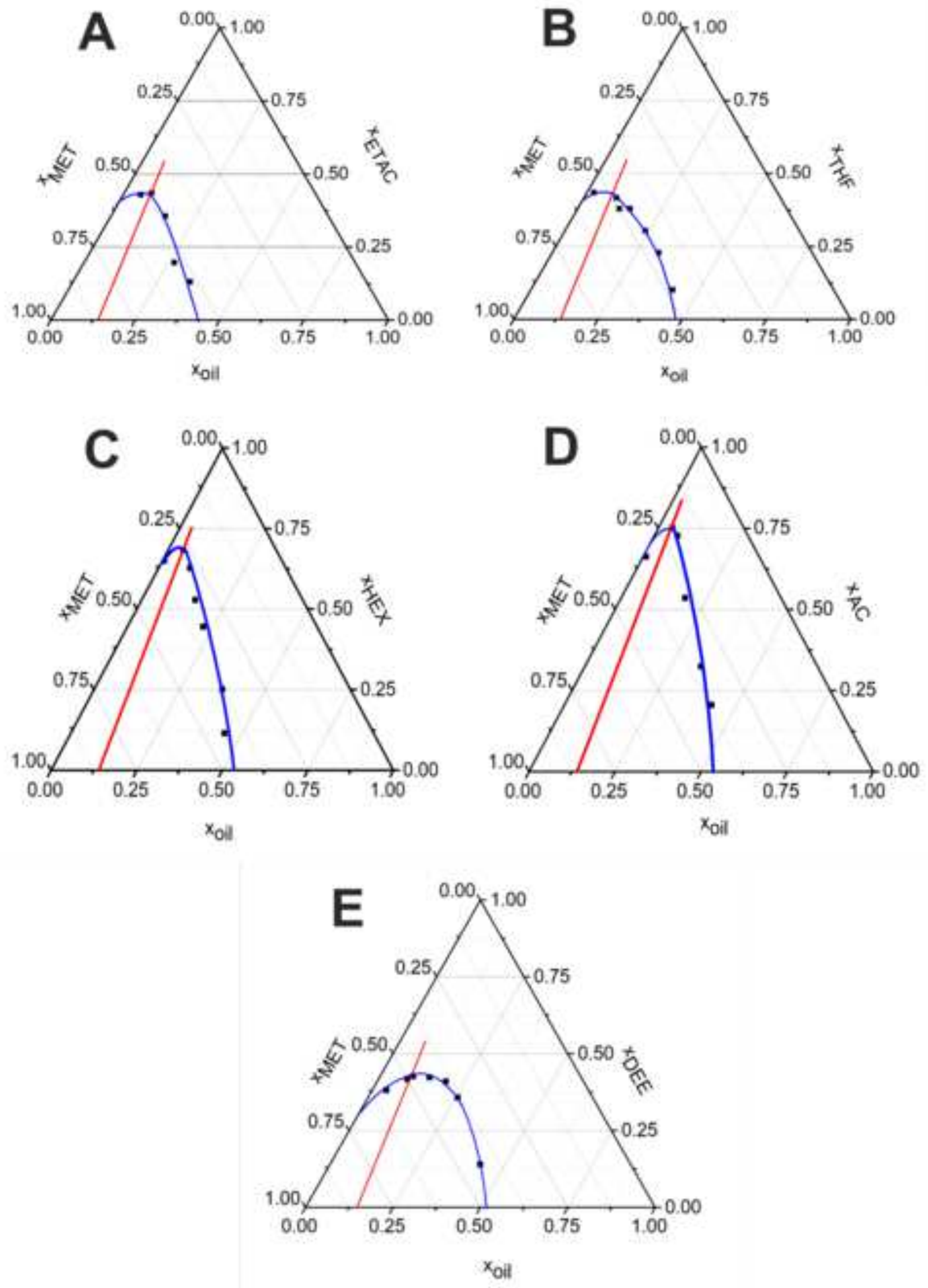


\section{Figure 3}

Click here to download high resolution image

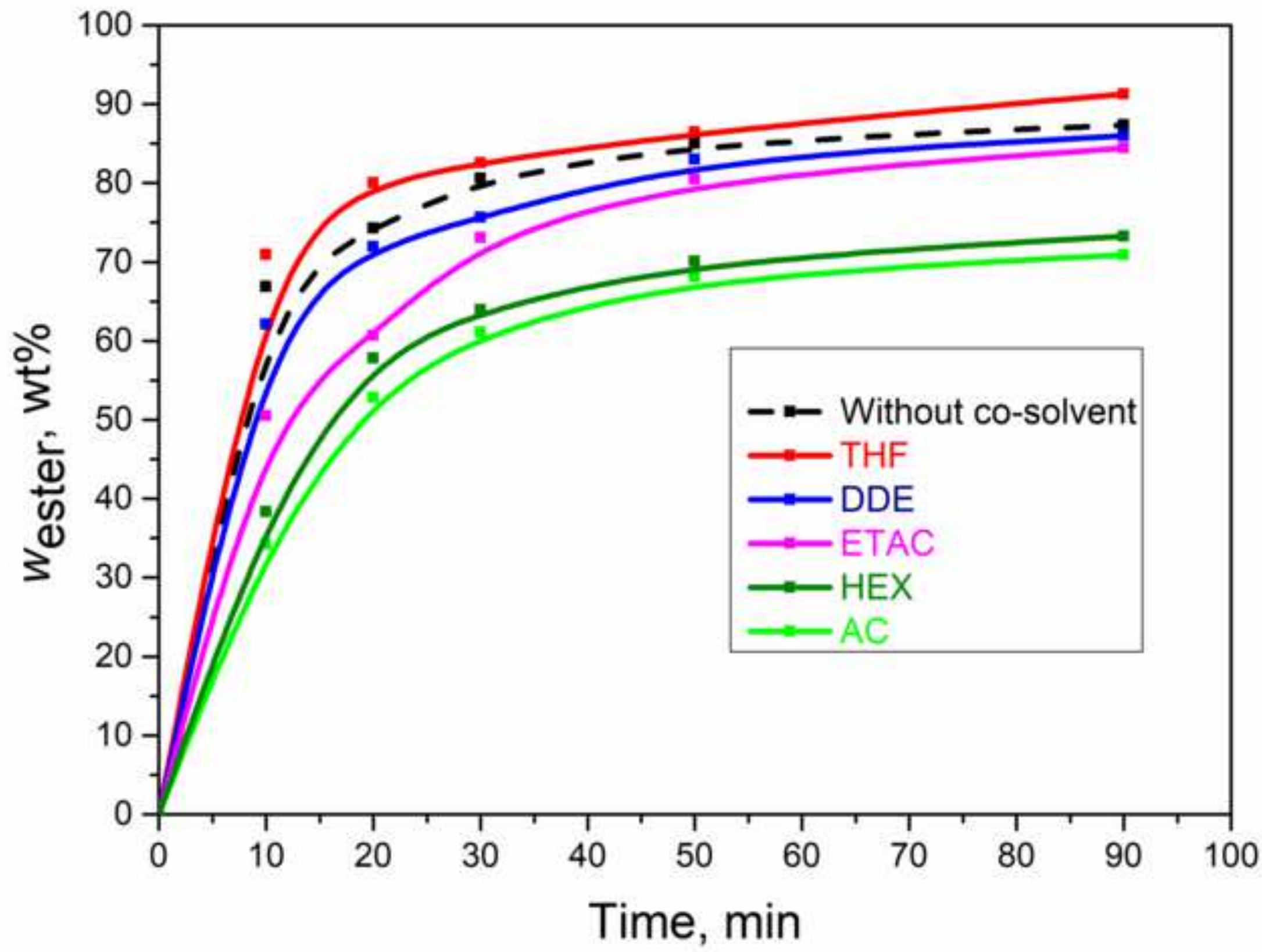



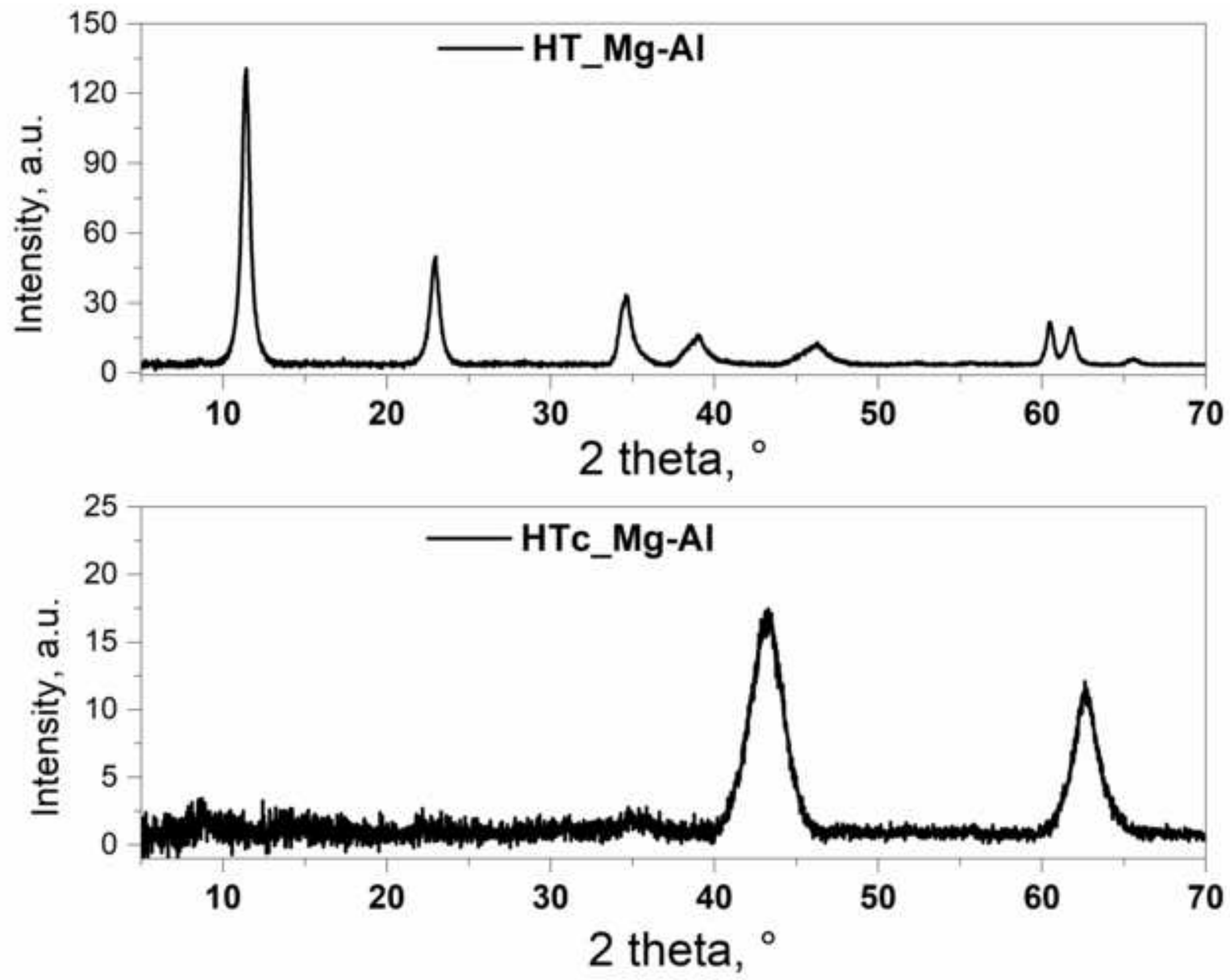


\section{HT_Mg-Al}
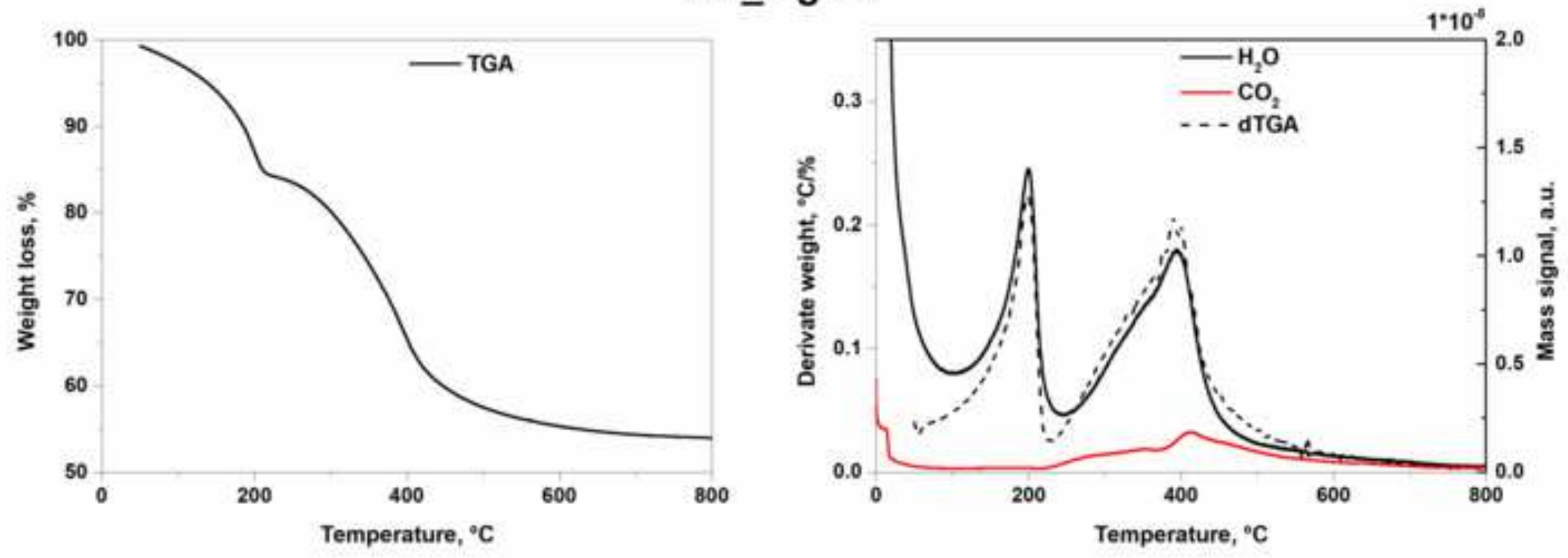

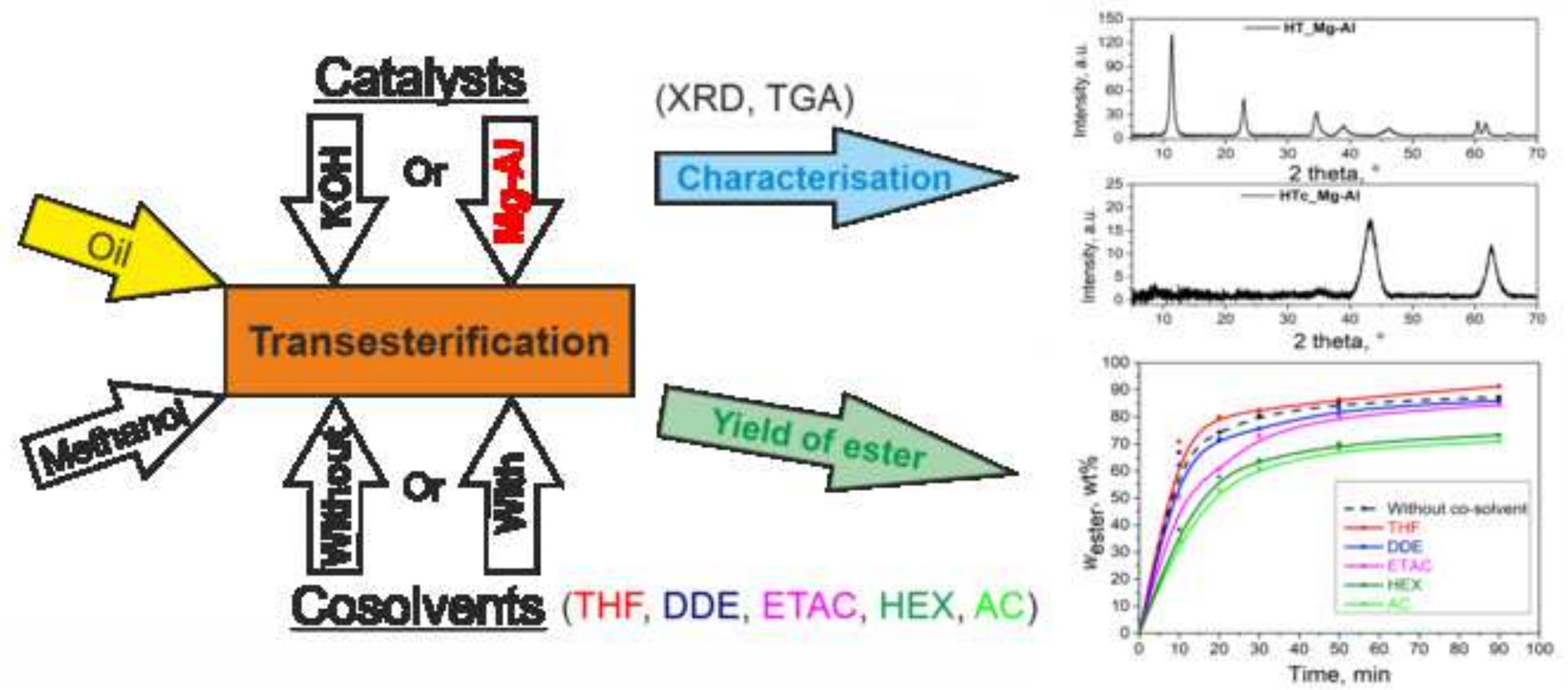
Table 1: The chosen properties of cosolvents and methanol including the minimum molar ratio of components for the mixture is in the single phase

\begin{tabular}{l|cccccc}
\hline \multicolumn{1}{c|}{ Type of cosolvent } & Methanol & ETAC & THF & AC & DEE & HEX \\
\hline $\begin{array}{l}\text { Boiling point at standard } \\
\text { pressure, }{ }^{\circ} \mathrm{C}\end{array}$ & 64.7 & 77.1 & 66 & 56.5 & 34.6 & 68.5 \\
$\begin{array}{l}\text { Density }\left(20{ }^{\circ} \mathrm{C}\right), \mathrm{g} \mathrm{cm}^{-3} \\
\text { Dynamic viscosity }\left(20^{\circ} \mathrm{C}\right),\end{array}$ & 0.79 & 0.89 & 0.89 & 0.79 & 0.71 & 0.66 \\
mPa s & 0.59 & 0.45 & 0.55 & 0.32 & 0.24 & 0.31 \\
Electric dipole moment, $\mathrm{C} \mathrm{m}$ & 1.69 & 1.78 & 1.63 & 2.91 & 1.15 & 0.08 \\
Relative permittivity $\left(20^{\circ} \mathrm{C}\right),-$ & 32.7 & 1.37 & 7.58 & 20.7 & 4.33 & 1.89 \\
Water content, wt $\%$ & 0.03 & 0.02 & 0.03 & 0.25 & 0.15 & 0.05 \\
Molar ratio oil:MET:cosolvent, & - & $1: 6: 5.5$ & $1: 6: 6$ & $1: 6: 24.5$ & $1: 6: 5$ & $1: 6: 15$ \\
\hline
\end{tabular}


Table 2. The properties of the EP after transesterification with various cosolvents

\begin{tabular}{l|cc|cc|c|c|cc|cc}
\hline Type of cosolvent & \multicolumn{2}{|c|}{ ETAC } & \multicolumn{2}{c|}{$\mathrm{THF}$} & \multicolumn{2}{c|}{$\mathrm{AC}$} & \multicolumn{2}{c}{ DEE } & \multicolumn{2}{c}{$\mathrm{HEX}$} \\
\hline \multicolumn{1}{c|}{ Way of stop } & $\mathrm{CO}_{2}$ & $\mathrm{H}_{3} \mathrm{PO}_{4}$ & $\mathrm{CO}_{2}$ & $\mathrm{H}_{3} \mathrm{PO}_{4}$ & $\mathrm{CO}_{2}$ & $\mathrm{H}_{3} \mathrm{PO}_{4}$ & $\mathrm{CO}_{2}$ & $\mathrm{H}_{3} \mathrm{PO}_{4}$ & $\mathrm{CO}_{2}$ & $\mathrm{H}_{3} \mathrm{PO}_{4}$ \\
\hline$w_{M G}(\mathrm{wt} \%)$ & 12.35 & 12.55 & 5.18 & 4.59 & 4.06 & 4.39 & 11.10 & 10.75 & 3.92 & 3.85 \\
$w_{D G}(\mathrm{wt} \%)$ & 7.85 & 7.55 & 2.28 & 2.47 & 4.33 & 4.60 & 3.82 & 2.41 & 4.40 & 4.21 \\
$w_{T G}(\mathrm{wt} \%)$ & 8.99 & 8.66 & 1.26 & 1.31 & 5.58 & 5.11 & 2.51 & 2.37 & 5.08 & 4.95 \\
$w_{\text {ester }}(\mathrm{wt} \%)$ & 70.8 & 71.2 & 91.3 & 91.6 & 86.0 & 85.9 & 82.6 & 84.5 & 86.6 & 87.0 \\
$\rho\left(\mathrm{g} \mathrm{cm}^{-3}\right)$ & 0.84 & 0.88 & 0.82 & 0.88 & 0.86 & 0.89 & 0.89 & 0.89 & 0.87 & 0.88 \\
$v\left(\mathrm{~mm}^{2} \mathrm{~s}^{-1}\right)$ & 5.45 & 5.29 & 5.20 & 5.11 & 5.38 & 5.26 & 5.50 & 5.38 & 5.41 & 5.32 \\
an $\left(\mathrm{mg} \mathrm{KOH} \mathrm{g}^{-1}\right)$ & 0.10 & 0.25 & 0.24 & 0.24 & 0.11 & 0.31 & 0.31 & 0.30 & 0.12 & 0.25 \\
$w_{\text {water }}^{E P}(\mathrm{ppm})$ & 800 & 700 & 800 & 650 & 900 & 700 & 1000 & 1100 & 1000 & 800 \\
$K\left(\mathrm{mg} \mathrm{kg}^{-1}\right)$ & 97 & 84 & 72 & 60 & 250 & 240 & 66 & 57 & 220 & 230 \\
\hline
\end{tabular}


Table 3. The distribution of methyl esters according to higher fatty acid in the EP

\begin{tabular}{c|cccc}
\hline \multirow{2}{*}{$\begin{array}{c}\text { Type of } \\
\text { cosolvent }\end{array}$} & \multicolumn{4}{|c}{ Methyl esters of higher fatty acids (100\%) } \\
& Linolenic (\%) & Linoleic (\%) & Oleic (\%) & Palmitic (\%) \\
\hline Without & 11.00 & 21.70 & 62.10 & 5.21 \\
THF & 11.10 & 20.07 & 64.77 & 4.07 \\
AC & 14.50 & 21.11 & 58.41 & 5.98 \\
DEE & 10.78 & 21.37 & 57.49 & 10.35 \\
ETAC & 13.37 & 21.03 & 62.92 & 2.68 \\
HEX & 13.40 & 21.50 & 58.03 & 7.07 \\
\hline
\end{tabular}


Table 4. The composition of the GP after transesterification with various cosolvents

\begin{tabular}{c|cc|cc|c|c|cc|cc}
\hline $\begin{array}{c}\text { Type of } \\
\text { cosolvent }\end{array}$ & \multicolumn{2}{|c|}{ ETAC } & \multicolumn{2}{|c|}{$\mathrm{THF}$} & \multicolumn{2}{c|}{$\mathrm{AC}$} & \multicolumn{2}{c}{$\mathrm{DEE}$} & \multicolumn{2}{c}{$\mathrm{HEX}$} \\
\hline Way of stop & $\mathrm{CO}_{2}$ & $\mathrm{H}_{3} \mathrm{PO}_{4}$ & $\mathrm{CO}_{2}$ & $\mathrm{H}_{3} \mathrm{PO}_{4}$ & $\mathrm{CO}_{2}$ & $\mathrm{H}_{3} \mathrm{PO}_{4}$ & $\mathrm{CO}_{2}$ & $\mathrm{H}_{3} \mathrm{PO}_{4}$ & $\mathrm{CO}_{2}$ & $\mathrm{H}_{3} \mathrm{PO}_{4}$ \\
\hline$w_{\text {glycerol }}$ (wt\%) & 67.5 & 68.5 & 43.8 & 46.1 & 41.5 & 71.3 & 65.9 & 60.2 & 56.1 & 70.5 \\
$w_{\text {ester }}^{\text {GP }}(\mathrm{wt} \%)$ & 3.8 & 2.8 & 9.0 & 13.3 & 5.9 & 6.4 & 7.2 & 13.1 & 7.1 & 5.9 \\
$w_{\text {water }}^{\text {GP }}(\mathrm{wt} \%)$ & 0.41 & 0.48 & 0.24 & 0.68 & 0.88 & 1.04 & 0.69 & 0.79 & 0.85 & 0.99 \\
$w_{S}(\mathrm{wt} \%)$ & 33.3 & 35.6 & 30.3 & 31.9 & 29.2 & 18.4 & 28.7 & 22.2 & 28.3 & 19.5 \\
$w_{\mathrm{K}_{2} \mathrm{CO}_{3}}(\mathrm{wt} \%)$ & 3.1 & - & 4.8 & - & 5.5 & - & 5.6 & - & 5.2 & - \\
$w_{\mathrm{KHCO}_{3}}(\mathrm{wt} \%)$ & 0.19 & - & 0.45 & - & 0.43 & - & 0.36 & - & 0.51 & - \\
$w_{\mathrm{K}_{2} \mathrm{HOO}_{4}}(\mathrm{wt} \%)$ & - & 1.9 & - & 2.38 & - & 0.6 & - & 2.38 & - & 1.1 \\
\hline
\end{tabular}

